RETRACTION NOTE

\title{
Retraction Note to: Involvement of the GABA-Ergic System in Anxiolytic and Antidepressive Effects of the Scrophularia striata Extract in Rats
}

Springer Science+Business Media New York 2013

Retraction to: Neurophysiology 2013, 45(1):26-33

DOI 10.1007/s11062-013-9333-1

The article in Vol. 45, No. 1, 2013, pp. 26-33, entitled "Involvement of the GABA-Ergic System in Anxiolytic and Antidepressive Effects of the Scrophularia striata Extract in Rats," by Sh. Babri, M. Kosari-Nasab, L. Fatehi-Gharehlar, and M.-H. Doosti, has been retracted due to duplicate publication.

The online version of the original article can be found under doi: $10.1007 / \mathrm{s} 11062-013-9333-1$

M. Kosari-Nasab (*), L. Fatehi-Gharehlar

Laboratory of Plant Biotechnology, Hayyan Research Center,

University of Tabriz, Tabriz, Iran

e-mail: morteza.kosarinasab@yahoo.com

Sh. Babri

Neurosciences Research Center, Tabriz University of Medical Sciences,

Tabriz, Iran

M.-H. Doosti

Faculty of Medicine of the Tabriz University of Medical Sciences, Tabriz, Iran 